\title{
EMPRESAS DE REVESTIMENTO CERÂMICO E SUAS ESTRATÉGIAS COMPETITIVAS E DE PRODUÇÃO
}

\section{GESTÃO \\ $\&$ \\ PRODUÇÃO}

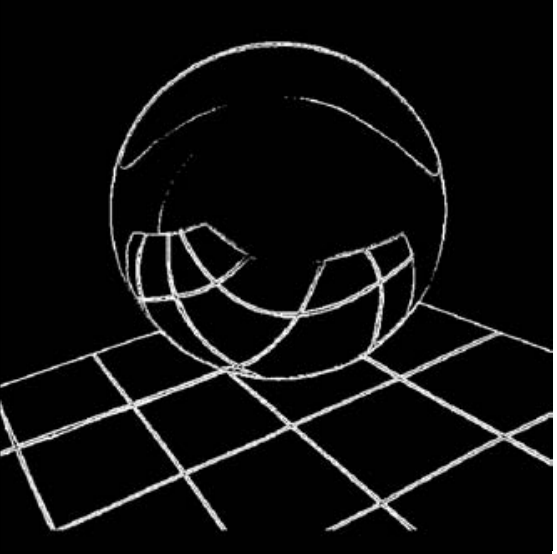

v.8, n.1, p.84-99, abr. 2001
Edemilson Nogueira Alceu Gomes Alves Filho Ana Lúcia Vitale Torkomian

Universidade Federal de São Carlos Departamento de Engenharia de Produção Via Washington Luiz, Km 235 - Cx Postal 676

São Carlos - SP

E-mails: edn@power.ufscar.br alceu@power.ufscar.br torkomia@power.ufscar.br

\section{Resumo}

Neste trabalho identificamos e discutimos as estratégias competitivas e de produção adotadas por doze empresas da indústria brasileira de cerâmica para revestimento. Realizamos entrevistas em empresas nos Estados de São Paulo e Santa Catarina e identificamos cinco grupos estratégicos. Os resultados obtidos mostram que existem muitas combinações possiveis de estratégias competitivas $e$ de produção. Mesmo dentro de cada grupo estratégico, encontramos estruturas de manufatura e sistemas administrativos muito diferenciados.

Palavras-chave: estratégia competitiva, estratégia de produção, empresa de revestimento cerâmico.

\section{Introdução}

Drocuramos neste artigo identificar e discutir as estratégias competitivas e de produção adotadas por algumas empresas do setor de revestimentos cerâmicos. Trata-se de um estudo exploratório que visa, fundamentalmente, fornecer os traços principais dos tipos de estratégias que podem ser encontrados nesse setor e os problemas comuns com que as empresas se defrontam.

Esse setor industrial foi escolhido por sua importância na economia brasileira, especialmente em alguns pólos industriais regionais, e por se tratar de um setor dinâmico, constituído por empresas de capital nacional, com amplas perspectivas de se tornar bastante competitivo no mercado internacional. Ainda, segundo 
informações preliminares que obtivemos, o setor apresentaria deficiências, no âmbito do planejamento estratégico e da gestão de produção, que eventualmente poderiam ser sanadas por meio de programas desenvolvidos pelas empresas individualmente ou em parceria com instituições governamentais ou privadas de apoio setorial.

Como já há na literatura alguma comprovação de que as estratégias competitivas e de produção contribuem para a competitividade das empresas (GUPTA \& LONIAL, 1998), entendemos que a realização deste estudo poderia contribuir para a formulação e aperfeiçoamento de programas de melhorias que fossem depois desenvolvidos e implementados pelas empresas ou pelas instituições de apoio ao setor.

Neste estudo procuramos realizar entrevistas com gerentes ou diretores (vinculados a áreas de produção) de empresas que pudessem representar segmentos estratégicos distintos no setor. Assim, realizamos entrevistas em empresas de grande porte e de pequeno porte; em empresas com marcas conhecidas e em outras com marcas pouco conhecidas; em empresas cujos produtos eram fabricados por via seca e em outras com produtos fabricados por via úmida; em empresas localizadas em Santa Catarina e em empresas localizadas no Estado de São Paulo, num total de 12 empresas.

As informações preliminares sobre as empresas foram obtidas no CCB (Centro Cerâmico do Brasil), que nos forneceu também apoio para realização de parte desta pesquisa. $\mathrm{O}$ trabalho aqui apresentado consiste em um módulo de um projeto mais amplo relacionado à Estratégia Tecnológica e de Produção do Setor de Cerâmica para Revestimento, financiado pela FAPESP.

Para a identificação dos tipos de estratégias adotados aplicamos nas entrevistas um roteiro com "perguntas abertas", abrangendo características gerais das empresas como produtos, segmentos de mercado, estrutura organizacional, processos de produção, relações com fornecedores, controle de qualidade e de produção. Procuramos explorar em cada entrevista os aspectos que considerávamos diferenciadores da empresa em questão (em relação às demais) e os seus principais problemas, buscando ampliar nossa compreensão sobre as características do universo das empresas e sobre a amplitude dos problemas do setor. Cada entrevista durou cerca de duas horas, sendo seguida de uma visita ao chão-de-fábrica que em média durou cerca de uma hora.

Antes de apresentarmos os resultados dessa pesquisa empírica, faz-se necessário indicar, ainda que de maneira breve, a estrutura conceitual que a orienta.

\section{Estratégia Competitiva e Estratégia de Produção}

- stratégia competitiva é o conjunto de planos, políticas, programas e ações desenvolvidos por uma empresa ou unidade de negócios para ampliar ou manter, de modo sustentável, suas vantagens competitivas frente aos concorrentes. Para OHMAE (1983, p.36):

“... Sem competidores não haveria necessidade de estratégia, pois o único propósito do planejamento estratégico é tornar a empresa apta a ganhar, tão eficientemente quanto possível, uma vantagem sustentável sobre seus concorrentes...".

Para PORTER (1985, p.1), “a estratégia competitiva visa estabelecer uma posição lucrativa e sustentável contra as forças que determinam a competição industrial". O nível de competitividade alcançado pela empresa ou unidade de negócios depende de fatores sistêmicos, estruturais ou empresariais, segundo COUTINHO \& FERRAZ (1994), relacionados, respectivamente, às condições macroeconômicas, político-institucionais, regulatórias, infraestruturais e sociais do país onde a empresa está instalada; às características do mercado, da concorrência e da configuração da indústria ou setor econômico em que a empresa atua; e à capacidade gerencial e operacional da própria empresa. Cabe notar que, embora os dois 
primeiros conjuntos de fatores refiram-se a condicionantes externos à empresa, o posicionamento estratégico desta - e portanto suas decisões e ações - é que irá definir o impacto de tais oportunidades e ameaças do ambiente externo em seu desempenho. Segundo MONTGOMERY \& PORTER (1998), o desafio enfrentado pela gerência consiste em escolher ou criar um contexto ambiental em que as competências e recursos da empresa possam produzir vantagens competitivas.

Quanto aos fatores estruturais relacionados à competitividade das empresas, PORTER (1985) indica cinco forças que determinam a dinâmica da competição em uma indústria: a entrada de novos concorrentes, a ameaça de substitutos, o poder de barganha dos clientes, o poder de barganha dos fornecedores e a rivalidade entre os concorrentes atuais.

"A pressão coletiva destas cinco forças determina a habilidade das firmas em uma indústria de ganhar, em média, taxas de retorno sobre o investimento em excesso ao custo de capital. A pressão das cinco forças varia de indústria para indústria e pode se modificar quando a indústria evolui..." (PORTER, 1985, p.4).

As empresas em geral podem adotar três tipos de estratégia competitiva, segundo PORTER (1980): estratégia de liderança em custos, estratégia de diferenciação e estratégia de foco. A primeira visa obter vantagens competitivas pela oferta de produtos e serviços (em geral padronizados) a custos mais baixos do que os concorrentes. A segunda busca alcançar vantagens pela introdução de um ou mais elementos de diferenciação nos produtos e serviços, que justifiquem preços mais elevados. E o terceiro tipo de estratégia objetiva obter vantagens competitivas ou pela oferta de produtos e serviços com menores custos, ou pela diferenciação dos mesmos, mas em um segmento de mercado mais localizado ou restrito.

Ainda segundo PORTER (1980), é possível desenvolver o conceito de estratégias genéricas a partir da descrição de dimensões estratégicas como as seguintes: amplitude da linha de produto, segmento de clientes alvo, mercado geográfico atendido, identificação com a marca, canal de distribuição utilizado, posição de custo, serviços ao cliente, qualidade do produto e política de preços, dentre outras. A estratégia competitiva de uma empresa, em particular, pode ser descrita a partir do detalhamento dessas dimensões, ou de outras que sejam acrescentadas com o intuito de tornar a análise mais detalhada.

$\mathrm{Na}$ maioria dos segmentos industriais as empresas utilizam-se de estratégias competitivas distintas. Entretanto, é possível classificá-las em grupos estratégicos que, segundo PORTER (1980), podem ser definidos como grupos de empresas em uma indústria que estão seguindo estratégicas idênticas ou semelhantes ao longo das dimensões estratégicas. As empresas de um mesmo grupo estratégico, além de possuírem estratégias gerais parecidas, ainda se assemelham pelos seguintes fatos: tendem a ter fatias de mercado semelhantes, são afetadas e reagem de maneira similar aos acontecimentos ocorridos no âmbito da indústria a que pertencem.

A estratégia competitiva de uma empresa será desdobrada em geral em estratégias funcionais como as estratégias de marketing, de produção, financeira e tecnológica, buscando-se compor um todo coeso e harmônico de planos e ações que propiciem a aquisição de vantagens competitivas pela melhoria dos processos de negócios ou de elementos na "cadeia de valor" (PORTER, 1985) da empresa. A estratégia competitiva inclui os objetivos de mais longo prazo da empresa ou da unidade de negócios que serão repassados às estratégias funcionais. $\mathrm{E}$, em geral, está baseada em competências acumuladas durante período de tempo relativamente longo.

A estratégia competitiva adotada fica assim caracterizada pelo modo com que a empresa atende seus clientes. Como destaca OHMAE (1998), a estratégia será boa quando possibilitar entender melhor as necessidades dos clientes e criar valor para eles. Segundo PORTER (1985), a vantagem competitiva advém do valor que a 
empresa cria para seus clientes, em excesso ao custo que tem para criá-lo.

Assim, o planejamento estratégico propicia que a empresa identifique em que direção predominante pretende mover-se, orientando as competências (que vai acumulando e adquirindo) para as oportunidades que surgem no mercado de criar valor para seus clientes atuais e potenciais. A longo prazo, segundo PRAHALAD \& HAMEL (1998), a competitividade resulta da capacidade da empresa em formar competências para a criação e desenvolvimento de produtos e serviços que em geral não podem ser antecipados.

Como já afirmamos, a estratégia competitiva deve ser desdobrada nas estratégias funcionais de marketing, produção, tecnologia, finanças e outras, dependendo da estrutura organizacional da empresa (que também depende de sua estratégia). Nosso foco recai aqui sobre a estratégia de produção, cujo conceito é relativamente recente e formulado pioneiramente por SKINNER (1969).

Autores como HAYES (1985), WHEELWRIGHT (1984), SKINNER (1974), HÖRTE et al. (1987), LEONG, SNYDER \& WARD (1980) e VANALLE (1995) caracterizam a estratégia de produção como uma coleção de decisões individuais que afetam a capacidade da empresa em encontrar seus objetivos a longo prazo. Segundo esses autores, as prioridades competitivas necessárias para competir com sucesso deveriam refletir a estratégia de negócios e também fornecer o critério ou missão que, juntamente com as áreas de decisão, seria avaliada. Essa missão, geralmente, é representada por cinco diferentes dimensões ou prioridades competitivas da produção: custo, entrega, flexibilidade, qualidade e serviço (GARVIN, 1993).

Tais prioridades devem orientar todas as decisões, os programas e as ações implementados nas áreas de decisão estruturais (localização e capacidade, instalações e equipamentos, tecnologia de produto e processo e integração vertical) e infra-estruturais (organização, gestão de recursos humanos, logística e planejamento e controle da produção e gestão da qualidade).
Assim, concluímos que a estratégia de produção constitui-se dos planos, políticas e programas de ações implementados pela empresa, mais especificamente pela função produção (nas áreas de decisão), para que as prioridades competitivas da produção (custo, entrega, flexibilidade, qualidade e serviço) sejam alcançadas, em consonância com as demais estratégias funcionais e com a estratégia competitiva da empresa (VANALLE, 1995).

O conteúdo de uma estratégia de produção, contemplando prioridades e áreas de decisão, e sua subordinação à estratégia competitiva da empresa estão ilustrados na Figura 1.

Mais recentemente, alguns pesquisadores têm procurado incorporar ao modelo de conteúdo da estratégia de produção apresentado os programas JIT e TQM, a lean production e o CIM e ainda a abordagem de processos de negócios (MILLS, PLATTS \& GREGORY, 1995), o que denota uma (ou várias) teoria em construção. As questões relacionadas aos tradeoffs, por exemplo, dividem em correntes de pensamento a literatura sobre o assunto.

Com relação à abordagem por processos de negócios, que parece ser promissora, ADAIR \& MURRAY (1996) e MILLS, PLATTS \& GREGORY (1995) indicam os processos fundamentais nas organizações: o projeto e desenvolvimento de produtos; o projeto e desenvolvimento de processos; a geração e acompanhamento de pedidos; a execução de pedidos ou a produção; o provimento de suprimentos e a distribuição; o atendimento ao cliente. Os demais processos como, por exemplo, organização, sistemas de informação, motivação e cultura, finanças e contabilidade seriam processos de apoio. Todos esses processos apresentam intersecções evidentes com as áreas funcionais tradicionais ou com as áreas de decisão da estratégia de produção, mas a idéia é a de que observar cuidadosamente os processos de negócios - analisando os valores agregados a cada etapa, as relações com processos secundários, os recursos empregados - levaria a aperfeiçoamentos substanciais ou ao redesenho desses processos, constituindo um novo meio de 


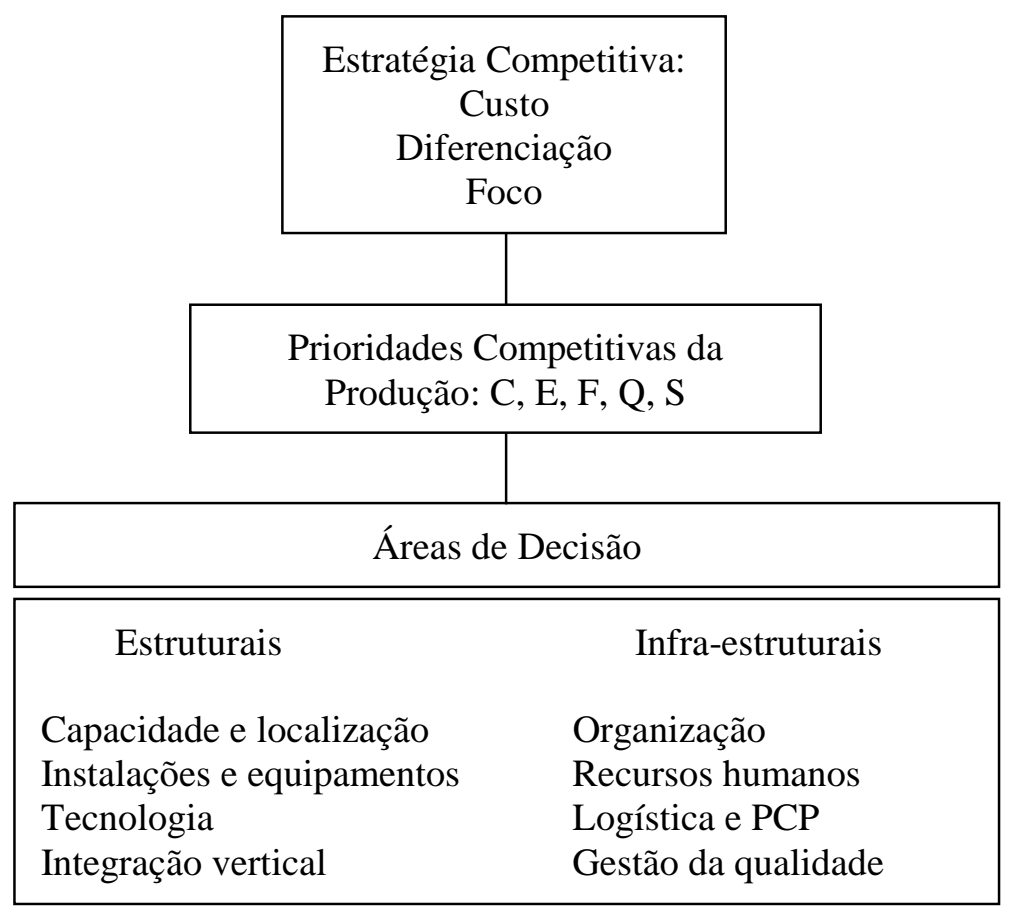

Figura 1 - Estratégia competitiva e estratégia de produção Fonte: adaptado de HÖRTE, LINDBERG \& TUNALV (1987)

se abordar a formulação e a implementação de uma nova estratégia de produção.

$\mathrm{Na}$ apresentação a seguir das características das estratégias competitivas e de produção de algumas empresas do setor de revestimentos cerâmicos, consideraremos os tipos de estratégias competitivas, as áreas de decisão e alguns dos processos de negócios mencionados acima. Entretanto, primeiramente faremos uma breve caracterização do setor.

\section{O Setor de Revestimentos Cerâmicos}

Teste item discorreremos inicialmente sobre 1 o mercado mundial de revestimentos cerâmicos e, em seguida, apresentaremos um panorama da indústria brasileira.

\subsection{O Mercado Mundial}

Nos últimos anos, a indústria de revestimentos cerâmicos, assim como todos os segmentos industriais, tem sofrido os efeitos da globaliza- ção da economia que, ao mesmo tempo em que mostra novas oportunidades de mercado, também apresenta ameaças às empresas participantes de um dado mercado nacional. Somam-se a esse fato outros aspectos como o nível de atividade da economia dos países, o desenvolvimento de produtos substitutos, o desempenho da indústria da construção civil de cada país etc. Em conjunto, esses fatores têm favorecido o crescimento da produção mundial de revestimentos, que se deve também a significativos avanços tecnológicos. Estes têm permitido às empresas aumentar a produtividade dos seus recursos e melhorar a qualidade dos produtos, atendendo às demandas do mercado.

O consumo mundial de revestimentos cerâmicos no ano de 1996 foi de aproximadamente 3.200 milhões de $\mathrm{m}^{2}$, destacando-se a posição ocupada pelo Brasil como o maior mercado consumidor $\left(303,1\right.$ milhões de $\left.\mathrm{m}^{2}\right)$. Dentre os cinco principais países consumidores em 1996, Brasil, China, Itália, Espanha e Alemanha, apenas este último não figura entre os cinco 
principais produtores, posto ocupado pela Indonésia (ASCER, 1999).

No que diz respeito às vendas para o mercado externo, os principais exportadores são Itália e Espanha, representando juntos 66,4\% do mercado no ano de 1996 (ASCER, 1999). Quanto aos países importadores, deve-se destacar a Alemanha, seguida dos Estados Unidos, França, Polônia e Reino Unido.

\subsection{A Indústria Brasileira}

A indústria cerâmica brasileira tem como principal origem as antigas fábricas de tijolos, blocos e telhas. Essas empresas, no início do século XX, começaram a fabricar ladrilhos hidráulicos e, posteriormente, azulejos e pastilhas de cerâmica e de vidro.

Atualmente o setor é constituído por 121 empresas com capacidade instalada de aproximadamente 455 milhões de $\mathrm{m}^{2}$ por ano. Em 1998 foram produzidos 400,7 milhões de $\mathrm{m}^{2}$, representando um índice de utilização da capacidade instalada de $88,1 \%$, dos quais 393,3 milhões de $\mathrm{m}^{2}$ foram comercializados (ANFACER, 1999).

A localização das empresas está fortemente concentrada nas regiões sul e sudeste, que integralizam $92 \%$ da capacidade instalada no país.

Embora as empresas estejam localizadas em 16 diferentes Estados da Federação, dados referentes ao ano de 1996 (ANFACER, 1997) mostram que São Paulo e Santa Catarina concentram $75 \%$ da produção total. Existem alguns fatores que poderiam justificar a alta concentração da produção nesses dois Estados, entretanto, um dos mais importantes é a proximidade dos maiores centros consumidores no país, que são as regiões sudeste e sul.

No que diz respeito ao mercado externo, essas regiões possuem uma localização privilegiada, pois estão próximas aos países do Mercosul, mercado com grande potencial a ser explorado. Também é importante destacar que as matérias-primas naturais, principais componen- tes do produto final, podem ser encontradas na maioria das regiões do país, reforçando a hipótese da relevância da localização da empresa perto do mercado consumidor.

Nas duas principais regiões produtoras de revestimentos cerâmicos, São Paulo e Santa Catarina, é possível identificar quatro pólos produtores onde aglutina-se um grande número de empresas. Os pólos são os seguintes:

- Região de Criciúma - Estado de Santa Catarina, abrangendo Tubarão, Urussanga e Ibituba;

- Região de São Paulo - Além da capital abrange Diadema, São Caetano, Suzano e Jundiaí;

- Região de Mogi-Guaçu - Estado de São Paulo;

- Região de Santa Gertrudes - Estado de São Paulo, abrangendo ainda Cordeirópolis, Rio Claro, Limeira e Araras.

Alguns dos grupos líderes em termos de produção possuem plantas em diferentes Estados. De acordo com SOUZA \& COVELO (1993), a estratégia desses grupos é possibilitar que seus produtos cheguem ao mercado consumidor com preços menores, uma vez que, tendo o produto baixo valor agregado, o custo de transporte é um importante componente do custo total do produto e, portanto, tem uma influência direta no preço final.

As exportações brasileiras, em 1998, cresceram $6,2 \%$ em relação ao ano anterior, atingindo o volume de 34,5 milhões de $\mathrm{m}^{2}$. Esse volume representou um faturamento de US\$ 155 milhões. O setor espera ainda apresentar um crescimento das exportações de $15 \%$ ao ano até 2002 (ANFACER, 1999).

As principais empresas exportadoras em 1997 foram Eliane (US\$ 31,4 milhões), Cecrisa (US\$ 30,2 milhões), Incepa (US\$ 25,6 milhões), Portobello (US\$ 25,1 milhões) e Chiarelli (US\$ 6,8 milhões) (QUARESMA, 1998).

Essas exportações são dirigidas predominantemente ao Mercosul, América do Norte e outros países da América Latina, que conjuntamente absorvem $85,5 \%$ das exportações brasileiras. 
Todavia, os produtos nacionais também são comercializados na Europa, África, Oceania e Ásia (ANFACER, 1999).

As empresas têm realizado algumas ações no sentido de aumentar suas vendas para o exterior como, por exemplo, a participação em feiras internacionais e o desenvolvimento de programas de melhoria tecnológica. Existe também a expectativa de que a consolidação do Mercosul possibilite a expansão das vendas nesse mercado que hoje já é muito importante.

Enfim, o volume de recursos financeiros que o setor movimenta, o número de pessoas que emprega e as divisas que gera ao país credenciamno como um dos mais importantes da nação. Assim, ações visando melhorar sua competitividade que tenham origem nas próprias empresas, nas associações de classe, nas universidades ou em agências governamentais devem ser incentivadas.

\section{Apresentação e Análise dos Resultados}

$\mathrm{U}$ ma síntese das informações obtidas na pesquisa de campo é apresentada nas tabelas a seguir. A Tabela 1 refere-se a aspectos da estratégia competitiva adotada pelas empresas (produtos e segmentos de mercado); na Tabela 2 constam os dados relativos à estrutura produtiva (correspondente às áreas de decisão estruturais da produção) e na Tabela 3 , os referentes à estrutura de gestão (áreas de decisão infra-estruturais).

A estratégia competitiva da empresa "A" caracteriza-se pela oferta de ampla linha de produtos tecnologicamente sofisticados, e de elevado padrão de qualidade, para segmentos de mercado com nível de renda alto. A abrangência desse mercado inclui todo o Brasil, além de uma fatia do mercado externo. Tendo como referência a abordagem de PORTER (1985), relativa às estratégias competitivas genéricas, pode-se afirmar que a empresa "A" adota uma estratégia que envolve foco e diferenciação, ou seja, direciona todas as suas atividades para atender um determinado grupo comprador, no caso o público de alto poder aquisitivo, e diferencia-se pelo produto e pela marca. Entre as prioridades competitivas descritas por GARVIN (1993), essa estratégia evidencia a qualidade, a flexibilidade e o nível de serviço. Evidentemente custos e entrega não deixam de ser relevantes, mas possuem grau de importância secundário.

Para viabilizar essa estratégia competitiva, a empresa "A" adota uma estratégia de produção com as seguintes características nas áreas estruturais: possui uma única planta com alta capacidade produtiva (a planta é dividida em unidades especializadas em determinados produtos), investe em desenvolvimento próprio de produtos, utiliza tecnologia de produto e de processo bem desenvolvida e possui um grau de integração vertical significativo. No que diz respeito às áreas infra-estruturais, implementa técnicas de controle de processo e de gestão da produção e da qualidade relativamente sofisticadas por meio de uma estrutura administrativa especializada e profissionalizada.

As empresas "B" e "C" apresentam características semelhantes à empresa "A" quanto à estratégia competitiva e de produção, embora diferenças substantivas as coloquem em um "grupo estratégico" diferente da empresa "A". Suas estratégias competitivas podem ser definidas como de diferenciação, enfatizando a marca e a qualidade de seus produtos que são direcionados a diferentes segmentos do mercado. A empresa "C", especificamente, atua com duas marcas, uma visando atingir consumidores de alto poder aquisitivo e outra, públicos de faixas de renda menores. O padrão de qualidade e o preço são estabelecidos de acordo com as características de cada um desses segmentos. Esse segundo grupo estratégico, assim como o anterior, tem como prioridades competitivas mais importantes a qualidade, a flexibilidade e o nível de serviço.

Para atender a essa estratégia competitiva, tanto a empresa "B" quanto a empresa "C" operam com volumes elevados de produção em diversas plantas distribuídas por alguns estados do país, contando com estruturas de produção e gestão relativamente sofisticadas e profissionalizadas. 
Tabela 1 - Estratégia Competitiva

\begin{tabular}{|c|c|c|c|c|c|c|c|c|c|c|c|c|}
\hline 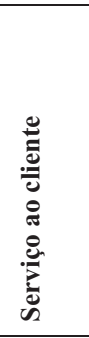 & 虍 & 感 & 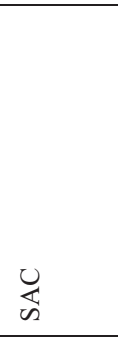 & 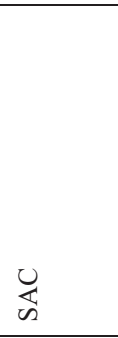 & 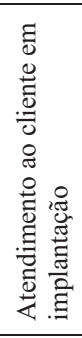 & 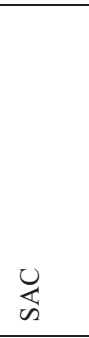 & 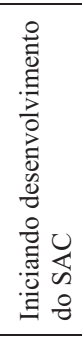 & 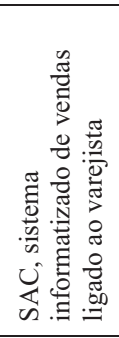 & 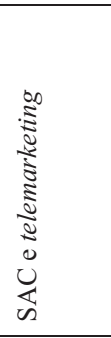 & 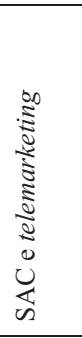 & 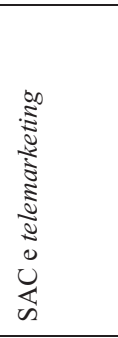 & 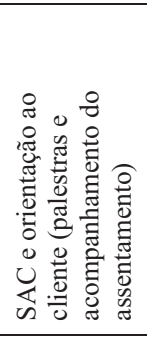 \\
\hline 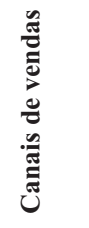 & 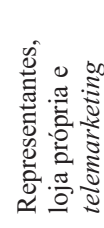 & 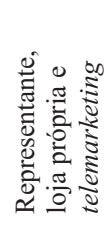 & 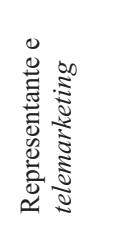 & 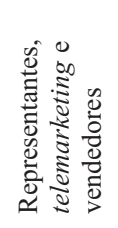 & 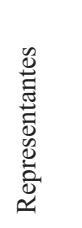 & 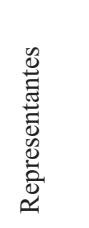 & 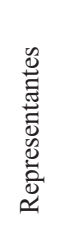 & 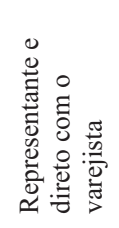 & 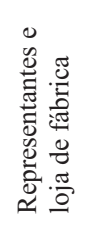 & 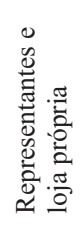 & 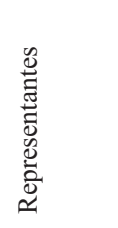 & 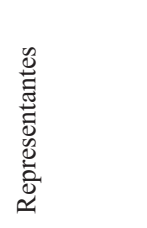 \\
\hline 节 & 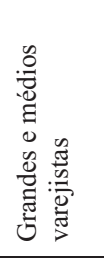 & 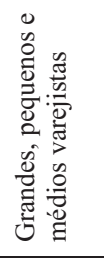 & 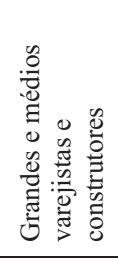 & 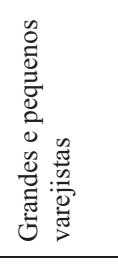 & 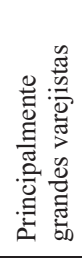 & 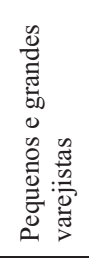 & 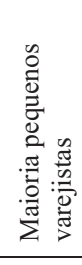 & 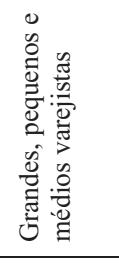 & 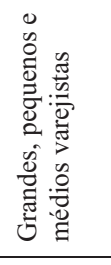 & 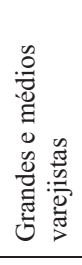 & 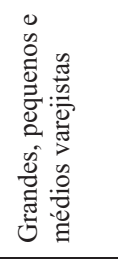 & 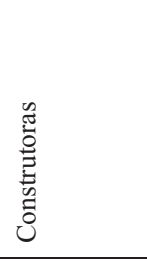 \\
\hline 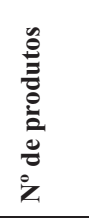 & 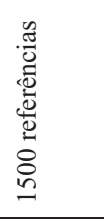 & 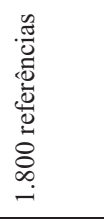 & 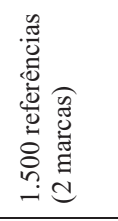 & 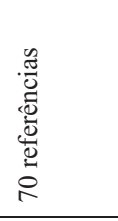 & 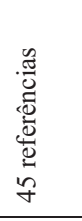 & 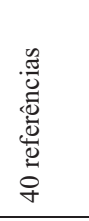 & 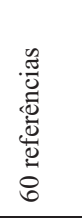 & 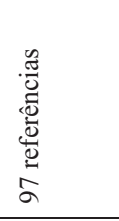 & 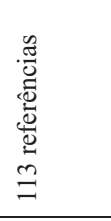 & 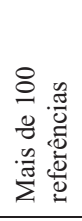 & 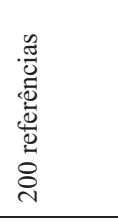 & 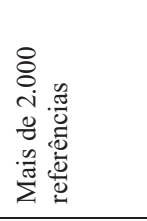 \\
\hline 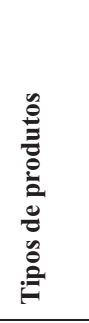 & 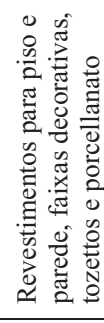 & 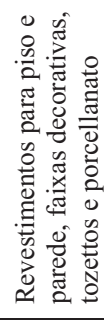 & 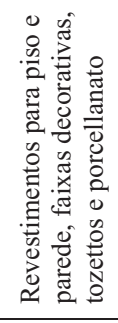 & 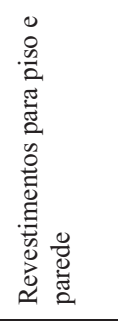 & 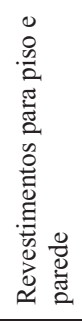 & 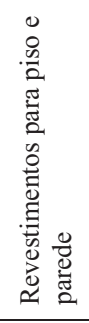 & 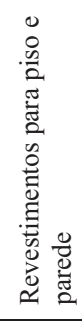 & 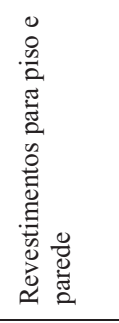 & 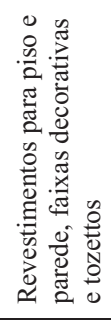 & 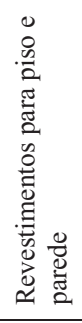 & 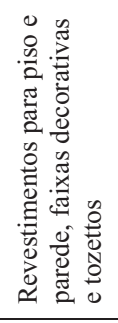 & 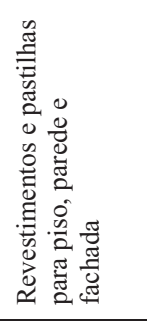 \\
\hline 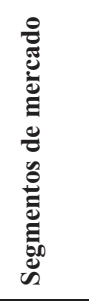 & 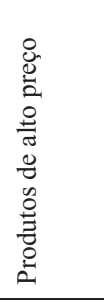 & 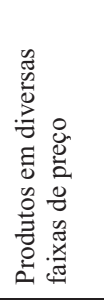 & 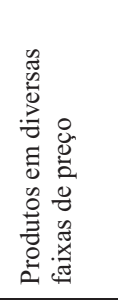 & 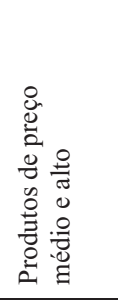 & 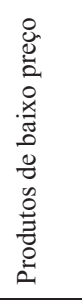 & 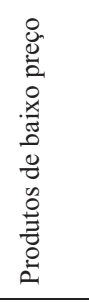 & 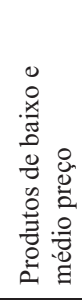 & 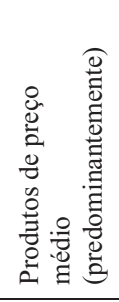 & 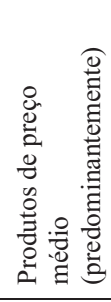 & 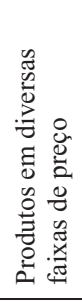 & 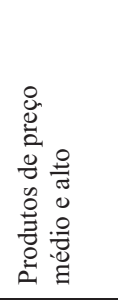 & 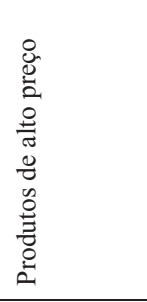 \\
\hline 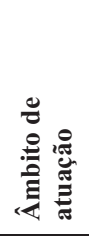 & 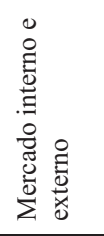 & 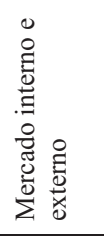 & 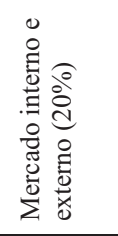 & 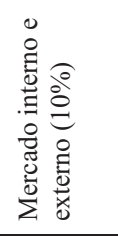 & 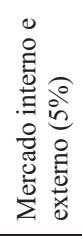 & 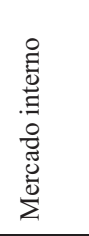 & 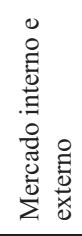 & 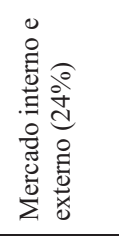 & 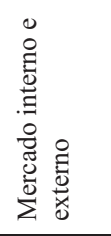 & 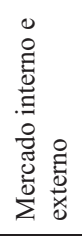 & 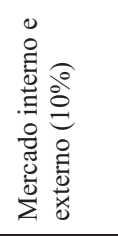 & 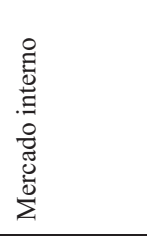 \\
\hline & 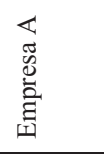 & 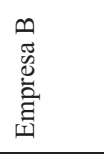 & 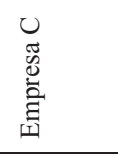 & 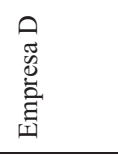 & 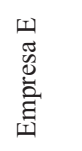 & 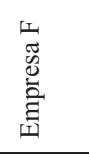 & 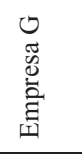 & 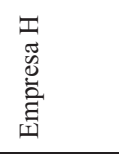 & 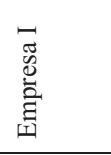 & 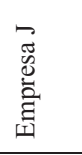 & 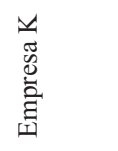 & 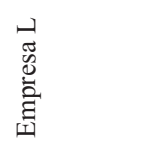 \\
\hline
\end{tabular}


Tabela 2 - Áreas Estruturais

\begin{tabular}{|c|c|c|c|c|c|c|c|c|c|c|c|c|}
\hline 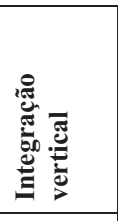 & 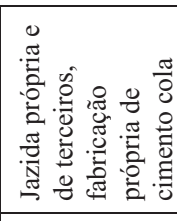 & 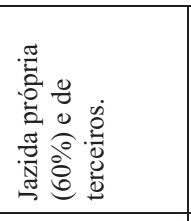 & 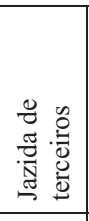 & 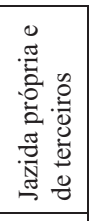 & 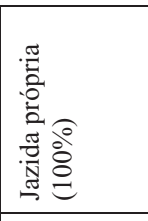 & 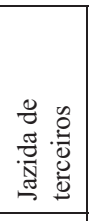 & 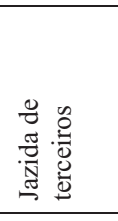 & 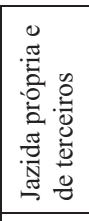 & 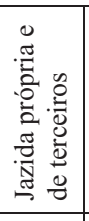 & 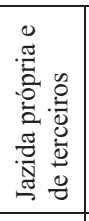 & 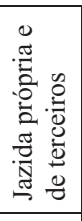 & 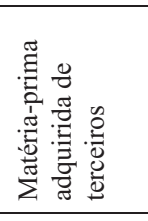 \\
\hline 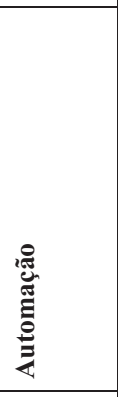 & 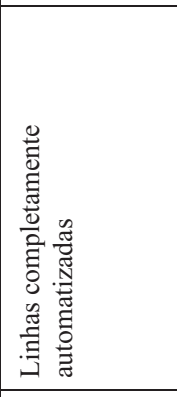 & 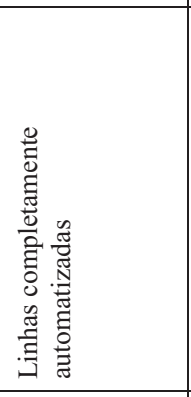 & 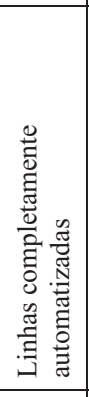 & 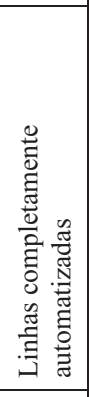 & 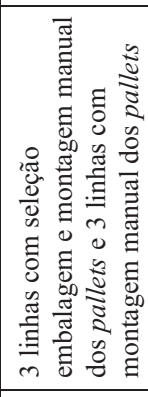 & 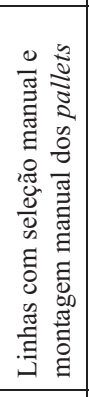 & 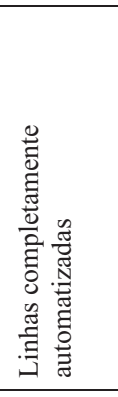 & 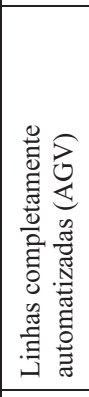 & 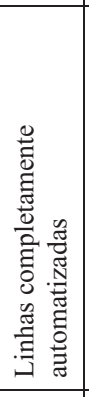 & 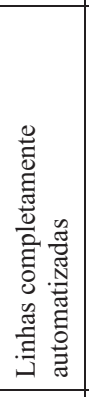 & 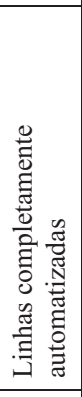 & 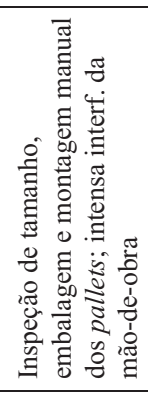 \\
\hline 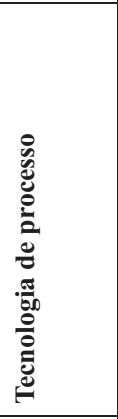 & 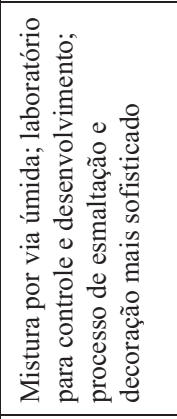 & 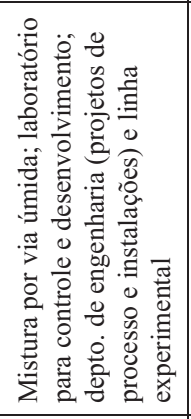 & 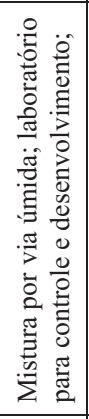 & 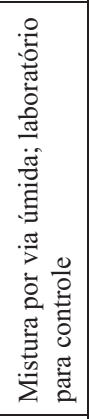 & 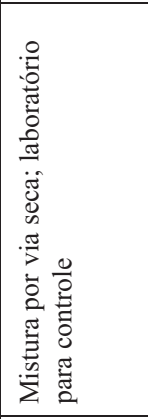 & 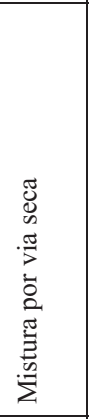 & 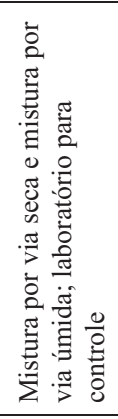 & 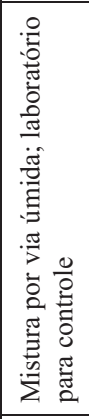 & 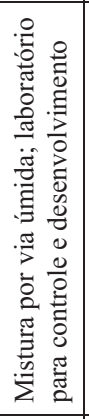 & 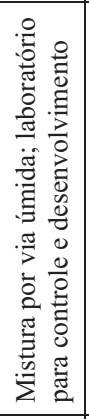 & 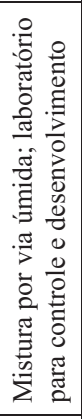 & 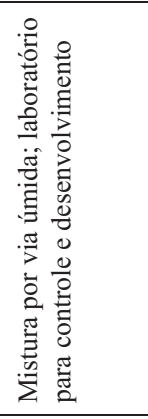 \\
\hline 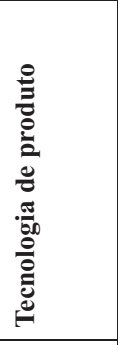 & 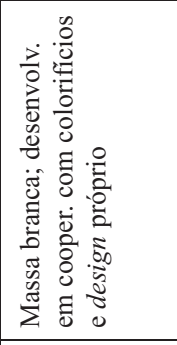 & 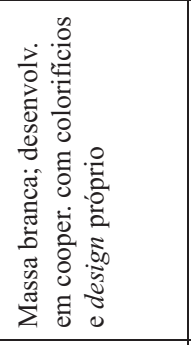 & 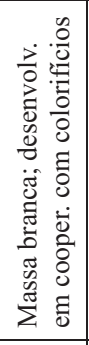 & 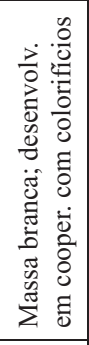 & 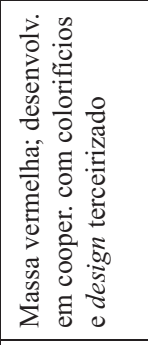 & 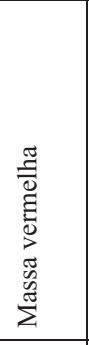 & 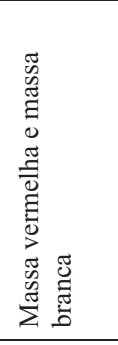 & 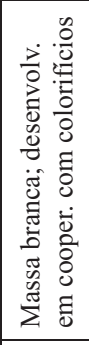 & 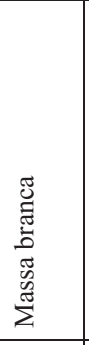 & 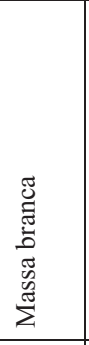 & 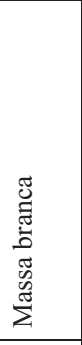 & 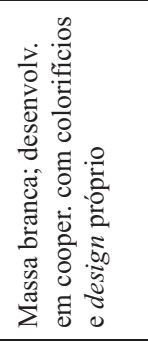 \\
\hline 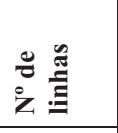 & 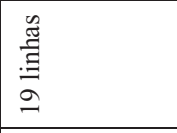 & & & 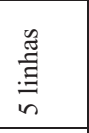 & 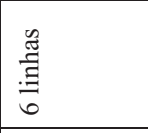 & $\begin{array}{l}\stackrel{0}{\mathbb{E}} \\
\stackrel{\Xi}{\Xi} \\
m\end{array}$ & 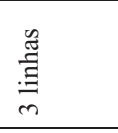 & 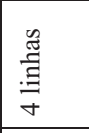 & $\begin{array}{l}\stackrel{\Xi}{\Xi} \\
\stackrel{\Xi}{\Xi} \\
\end{array}$ & 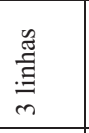 & ' & \\
\hline 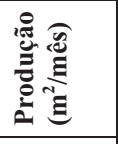 & 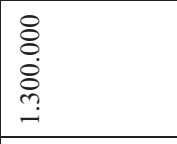 & $\begin{array}{l}8 \\
\vdots \\
0 \\
0 \\
0 \\
n \\
m\end{array}$ & 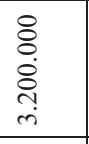 & $\begin{array}{l}8 \\
8 \\
0 \\
0 \\
\end{array}$ & 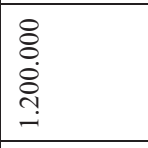 & $\begin{array}{l}8 \\
\stackrel{0}{0} \\
\dot{+} \\
\end{array}$ & $\begin{array}{l}8 \\
\vdots \\
0 \\
\text { in } \\
\end{array}$ & $\begin{array}{l}8 \\
8 \\
0 \\
0 \\
n \\
\end{array}$ & $\begin{array}{l}8 \\
\vdots \\
8 \\
\infty \\
\infty\end{array}$ & $\begin{array}{l}8 \\
\stackrel{0}{0} \\
\stackrel{\leftrightarrow}{7} \\
\end{array}$ & $\begin{array}{l}8 \\
\stackrel{0}{0} \\
\stackrel{\circ}{\circ}\end{array}$ & $\begin{array}{l}8 \\
\stackrel{0}{+} \\
\stackrel{+}{+} \\
\end{array}$ \\
\hline 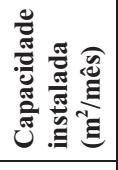 & $\begin{array}{l}8 \\
8 \\
8 \\
0 \\
\\
-1 \\
\end{array}$ & $\begin{array}{l}8 \\
8 \\
\circ \\
0 \\
\text { ले }\end{array}$ & $\begin{array}{l}\text { \&े } \\
\circ \\
0\end{array}$ & $\begin{array}{l}8 \\
8 \\
0 \\
\end{array}$ & \begin{tabular}{|l} 
\\
8 \\
0 \\
0 \\
0 \\
-1 \\
\end{tabular} & $\begin{array}{l}8 \\
8 \\
8 \\
\dot{8} \\
\end{array}$ & $\begin{array}{l}8 \\
8 \\
\circ \\
\vdots \\
1 \\
\end{array}$ & \begin{tabular}{|l|} 
\\
\\
8 \\
8 \\
\end{tabular} & $\begin{array}{l}\text { ڤे } \\
\dot{\leftrightarrow}\end{array}$ & $\begin{array}{l}8 \\
\stackrel{0}{0} \\
\text { भे }\end{array}$ & 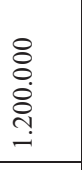 & $\begin{array}{l}8 \\
8 \\
8 \\
\end{array}$ \\
\hline 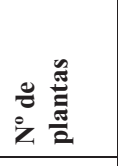 & 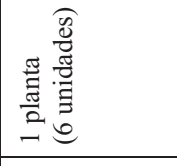 & 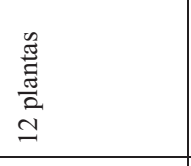 & $\begin{array}{l}\text { 节 } \\
\frac{\tilde{E}}{2} \\
\text { in } \\
\end{array}$ & 营 & 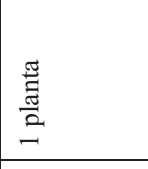 & 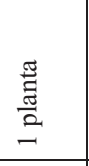 & 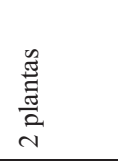 & 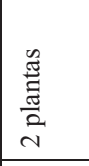 & $\begin{array}{l}\frac{\pi}{0} \\
\frac{\pi}{2} \\
\text { N }\end{array}$ & $\begin{array}{l}\frac{\pi}{0} \\
\frac{\pi}{2} \\
\sim \\
\end{array}$ & $\stackrel{\vec{\Xi}}{2}$ & $\frac{\text { ज }}{2}$ \\
\hline & 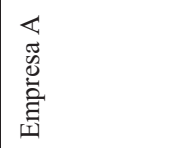 & 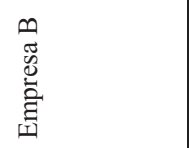 & 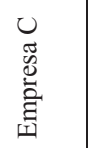 & 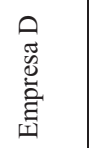 & 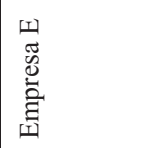 & 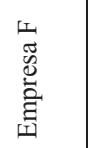 & 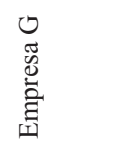 & 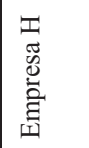 & 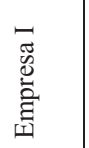 & 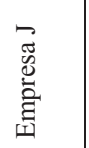 & 产 & 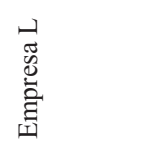 \\
\hline
\end{tabular}


Tabela 3 - Áreas Infra-estruturais

\begin{tabular}{|c|c|c|c|c|c|c|c|c|c|c|c|c|}
\hline 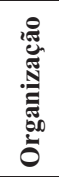 & 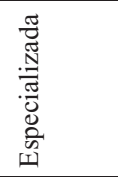 & 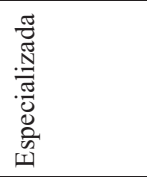 & 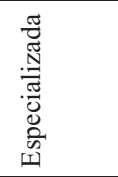 & 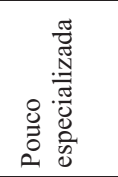 & 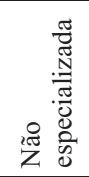 & 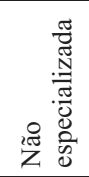 & 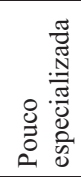 & 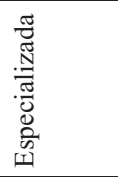 & 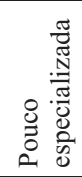 & 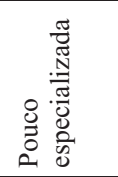 & 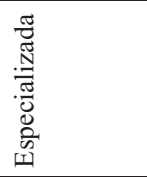 & 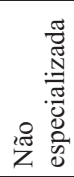 \\
\hline 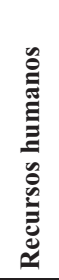 & 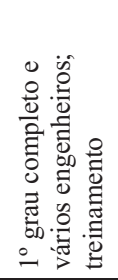 & 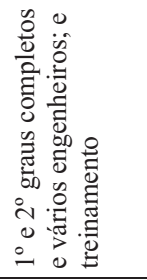 & 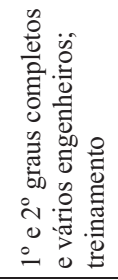 & 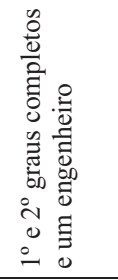 & 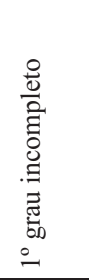 & 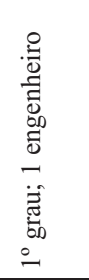 & 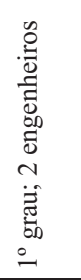 & 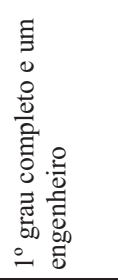 & 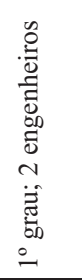 & 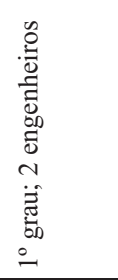 & 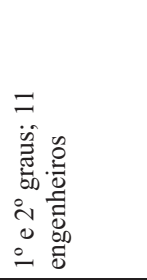 & 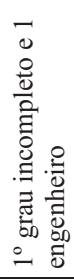 \\
\hline \multirow{4}{*}{ 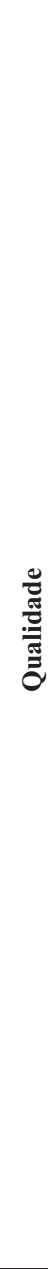 } & 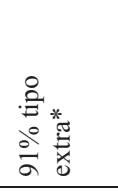 & 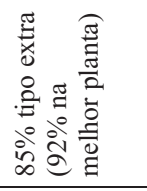 & ' & 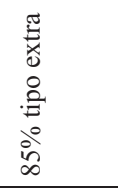 & 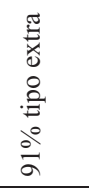 & 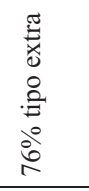 & 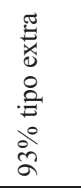 & 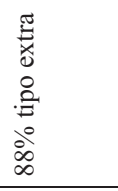 & 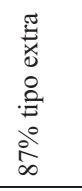 & 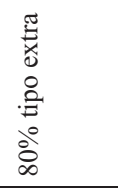 & 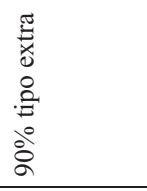 & 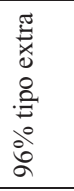 \\
\hline & 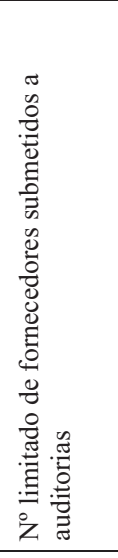 & 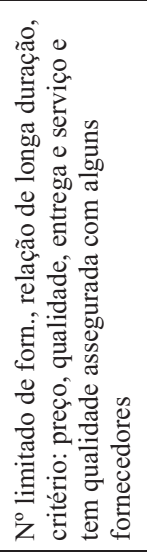 & 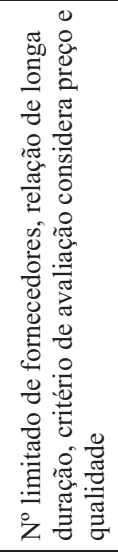 & 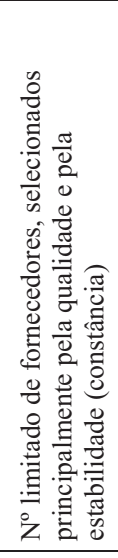 & 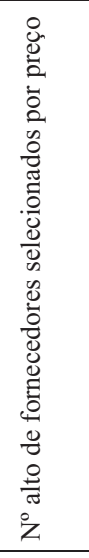 & 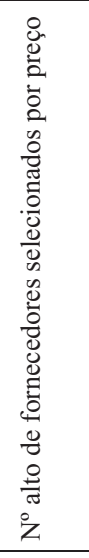 & 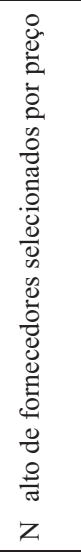 & 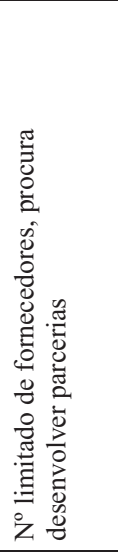 & 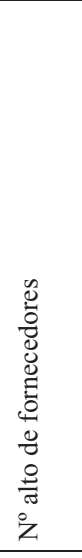 & 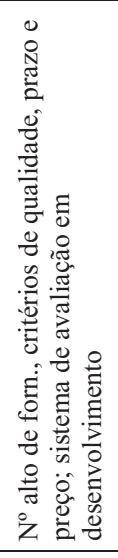 & 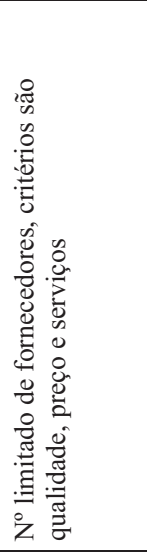 & 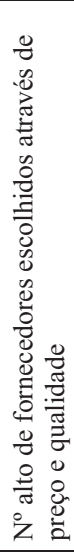 \\
\hline & 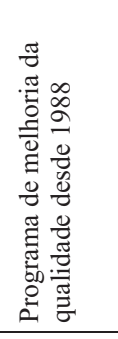 & 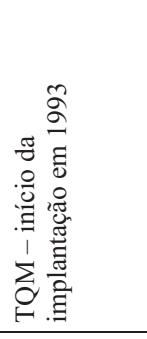 & 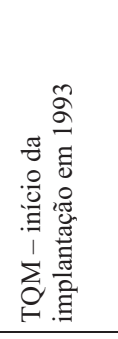 & 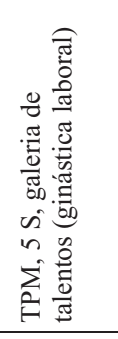 & 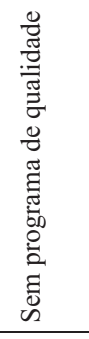 & 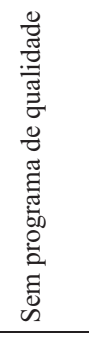 & 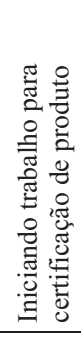 & 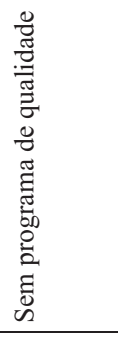 & 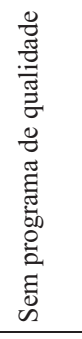 & 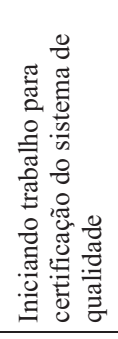 & 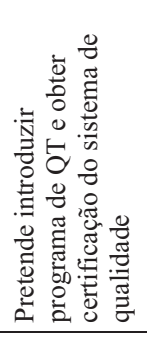 & 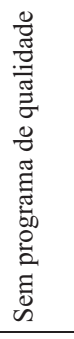 \\
\hline & 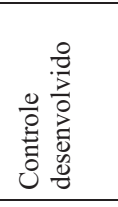 & 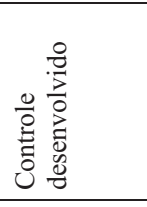 & 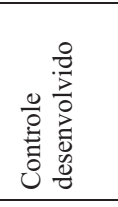 & 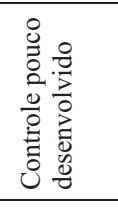 & 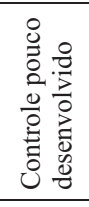 & 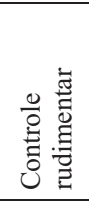 & 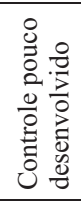 & 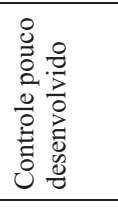 & 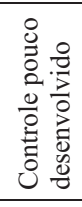 & 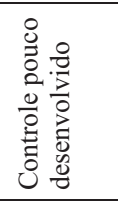 & 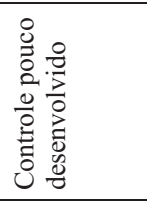 & 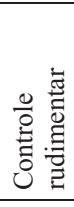 \\
\hline \multirow[t]{2}{*}{ రิ } & 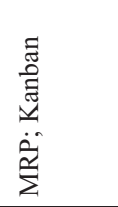 & $\tilde{\tilde{\Sigma}}$ & 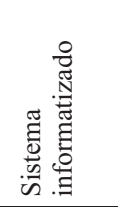 & 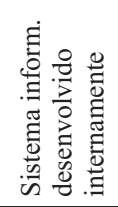 & 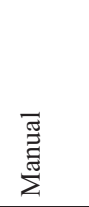 & 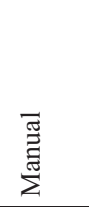 & 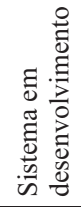 & 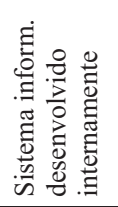 & 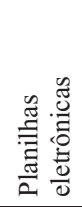 & $\begin{array}{l}\bar{\Xi} \\
\text { 丞 }\end{array}$ & 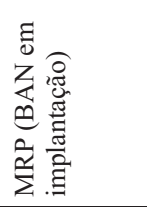 & 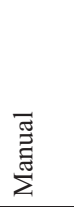 \\
\hline & 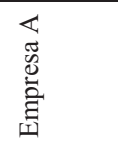 & 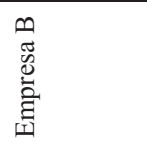 & 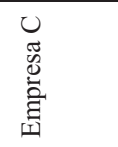 & 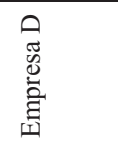 & 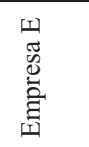 & 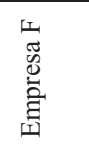 & 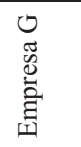 & 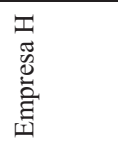 & 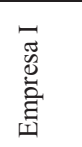 & 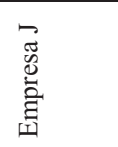 & 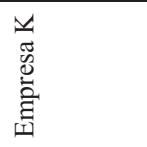 & 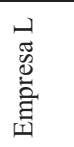 \\
\hline
\end{tabular}


As empresas "E" e "F" poderiam ser consideradas como representantes de outro "grupo estratégico", pois apresentam estratégias competitiva e de produção muito distintas das três empresas anteriores. Produzem um número pequeno de produtos em grandes lotes, utilizando tecnologia (massa vermelha e via seca) considerada menos sofisticada e complexa do que aquela (massa branca e via úmida) utilizada pelas demais empresas aqui analisadas, para atingir segmentos de mercado de renda mais baixa. Comparadas às empresas "A", "B" e "C", possuem estruturas organizacionais e de gestão da produção menos especializadas e profissionalizadas. Enquanto a empresa "A" adota uma estratégia competitiva de focalização/diferenciação e as empresas " $B$ " e "C" de diferenciação, com estratégias de produção orientadas para a qualidade dos produtos e para a flexibilidade, as empresas "E" e " $F$ " implementam estratégias competitivas de liderança em custo e estratégias de produção que viabilizam tal posicionamento.

As empresas "D", "H", "I", "J" e "K" possuem estratégias competitivas e de produção distintas das empresas anteriores e poderiam ser consideradas como pertencentes a um mesmo "grupo estratégico", embora dentro do próprio grupo sejam observadas diferenças nos parâmetros que definem tais estratégias. Em geral buscam ocupar posições de diferenciação pela qualidade, produzem pequena variedade de produtos e possuem capacidade de produção menor do que as empresas anteriores, exceto com relação à empresa "F", cuja capacidade instalada é de $500.000 \mathrm{~m}^{2}$ por mês. Orientam seus produtos, predominantemente, para segmentos intermediários de renda no qual a demanda é bastante sensível a variações de preço. Dentre as prioridades competitivas, as mais relevantes para esse conjunto de empresas são a qualidade e os custos de produção.

Para dar suporte a essa estratégia, as empresas desse quarto grupo centralizam a produção em uma ou duas plantas localizadas próximas ao principal mercado consumidor, empregam tecnologia de massa branca por via úmida e possuem estrutura organizacional e de gestão da produção pouco especializada e profissionalizada. Merece destaque, no caso da empresa "D", suas ações relacionadas à gestão da qualidade (TPM, 5S). A empresa " $\mathrm{H}$ " diferencia-se das demais empresas do grupo por terceirizar todo o desenvolvimento de produtos e de processos e possuir elevado nível de automação na produção. Cabe destacar, ainda, algumas particularidades da empresa "K", pois, neste grupo, é a empresa que possui maior variedade de produtos, maior capacidade instalada e maior número de profissionais de nível superior.

No caso da empresa "L" observa-se uma estratégia competitiva focada em uma determinada linha de produtos que visa atender um nicho específico de mercado (revestimentos para fachadas, desenvolvidos em alguns casos sob encomenda, para atender especialmente construtoras), caracterizando um quinto "grupo estratégico". Neste grupo a flexibilidade e os custos são fundamentais para a viabilizar o posicionamento de mercado.

A estratégia de produção de " $L$ " caracterizase pela fabricação de uma grande quantidade de produtos em baixos volumes, concentrados em uma única planta, pouco automatizada. Seu sistema de gestão é rudimentar e pouco profissionalizado.

A empresa " $G$ " não foi enquadrada em nenhum dos grupos acima, pois, por ocasião da visita, passava por um período de transição, envolvendo mudanças no processo de produção (via seca para via úmida), reformulação em sua linha de produtos, reprojeto das instalações industriais e sistemas de controle. De qualquer maneira, pode-se dizer que, anteriormente às mudanças, a empresa " $G$ " apresentava um posicionamento de mercado semelhante às empresas "E" e "F". Com as alterações que vêm sendo feitas, a tendência é que a empresa assuma estratégias competitiva e de produção próximas ao quarto grupo anteriormente descrito.

A Tabela 4 mostra o agrupamento das empresas de acordo com as estratégias competitivas genéricas adotadas. 
Tabela 4 - Grupos Estratégicos

\begin{tabular}{|c|c|c|c|c|}
\hline $\begin{array}{c}\text { Grupo } \\
\text { Estratégico }\end{array}$ & Empresa & $\begin{array}{l}\text { Estratégia } \\
\text { Competitiva } \\
\text { Genérica }\end{array}$ & $\begin{array}{l}\text { Prioridades } \\
\text { Competitivas }\end{array}$ & Dimensões Estratégicas \\
\hline 1 & A & $\begin{array}{l}\text { Foco (grupo } \\
\text { comprador) } \\
\text { /Diferenciação } \\
\text { (qualidade, marca, } \\
\text { variedade) }\end{array}$ & $\begin{array}{l}\text { Qualidade, } \\
\text { Flexibilidade e } \\
\text { Serviço }\end{array}$ & $\begin{array}{l}\text { Mercado interno e externo; } \\
\text { Segmento de mercado de alto poder } \\
\text { aquisitivo; } \\
\text { Marca forte; } \\
\text { Linha completa; } \\
\text { Alta variedade; } \\
\text { Qualidade alta (qualidade percebida, } \\
\text { estética, conformidade, durabilidade). }\end{array}$ \\
\hline 2 & $\mathrm{~B}$ e $\mathrm{C}$ & $\begin{array}{l}\text { Diferenciação } \\
\text { (qualidade, marca, } \\
\text { variedade) }\end{array}$ & $\begin{array}{l}\text { Qualidade, } \\
\text { Flexibilidade e } \\
\text { Serviço }\end{array}$ & $\begin{array}{l}\text { Mercado interno e externo; } \\
\text { Diversos segmentos de mercado; } \\
\text { Marca forte; } \\
\text { Linha completa; } \\
\text { Alta variedade; } \\
\text { Qualidade alta (qualidade percebida, } \\
\text { estética, conformidade, durabilidade). }\end{array}$ \\
\hline 3 & E e F & $\begin{array}{l}\text { Liderança no } \\
\text { Custo Total }\end{array}$ & Custo & $\begin{array}{l}\text { Predominantemente o mercado interno; } \\
\text { Segmento de mercado de baixa renda; } \\
\text { Linha reduzida; } \\
\text { Pouca variedade; } \\
\text { Qualidade com ênfase na conformidade. }\end{array}$ \\
\hline 4 & $\mathrm{D}, \mathrm{H}, \mathrm{I}, \mathrm{J}, \mathrm{K}$ & $\begin{array}{l}\text { Diferenciação } \\
\text { (qualidade) }\end{array}$ & $\begin{array}{l}\text { Qualidade e } \\
\text { Custo }\end{array}$ & $\begin{array}{l}\text { Mercado interno e externo; } \\
\text { Segmentos de mercado de renda } \\
\text { intermediária; } \\
\text { Linha média; } \\
\text { Variedade média; } \\
\text { Qualidade alta (conformidade, estética e } \\
\text { durabilidade). }\end{array}$ \\
\hline 5 & $\mathrm{~L}$ & $\begin{array}{l}\text { Enfoque (segmento } \\
\text { da linha de } \\
\text { produtos) }\end{array}$ & $\begin{array}{l}\text { Flexibilidade e } \\
\text { Custo }\end{array}$ & $\begin{array}{l}\text { Mercado interno; } \\
\text { Segmento específico de mercado; } \\
\text { Linha reduzida; } \\
\text { Alta variedade; } \\
\text { Qualidade (conformidade e durabilidade). }\end{array}$ \\
\hline
\end{tabular}

O estudo das doze empresas acima e a caracterização da indústria de revestimentos cerâmicos, a partir de fontes secundárias, nos permitem indicar algumas características essenciais das estratégias competitivas e de produção implementadas nesse setor e mencionar outras questões que requerem ainda algum esforço adicional de pesquisa para aprofundamento da discussão sobre as alternativas estratégicas das empresas.

Em primeiro lugar, constata-se ser este um setor dinâmico, com grande potencial de crescimento no país, que continuará, por algum tempo, envolvendo grupos de empresas com estratégias competitivas distintas. Tipos e 
variedade de produtos, segmentos de mercado, formas de atendimento aos clientes e tecnologias de produção podem ser combinadas, gerando diferentes estratégias. Como já destacamos, é interessante observar que alguns dos grupos estratégicos de empresas estão localizados concentradamente em algumas regiões dos Estados de Santa Catarina e de São Paulo.

Nossa análise indica que as empresas mais recentes, de menor porte, localizadas no pólo cerâmico de Santa Gertrudes (empresas "E" e "F"), e que utilizam tecnologia de preparação de massa por via seca (massa vermelha), tendem a adotar estratégias competitivas de liderança em custo e, portanto, têm suas alternativas de estratégia de produção direcionadas para o aumento da produtividade, a racionalização da produção, a integração vertical para trás e a utilização de canais tradicionais de distribuição e vendas. Nota-se que nesse segmento, embora a tecnologia utilizada seja menos sofisticada, as empresas em geral dependem mais do apoio dos fornecedores de equipamentos, materiais e de empresas de design. A qualificação da mão-deobra é relativamente baixa, as estruturas administrativas são pouco especializadas e os sistemas de gestão, rudimentares.

Já nas empresas localizadas em Santa Catarina (empresas "A", "B" e "C"), de maior porte e mais tradicionais, em que a tecnologia de massa branca por via úmida é utilizada, adotam-se estratégias competitivas de diferenciação que visam predominantemente segmentos de mais alta renda do mercado. Nessas empresas os equipamentos são também importados, mas já há um domínio maior da tecnologia envolvida no desenvolvimento de produtos e de processos e, também, na gestão da produção e da qualidade.

Outros grupos estratégicos podem ser identificados como ilustram os casos das empresas "D", "H", "I", "J" e "K", que direcionam seus produtos para conjuntos diferentes de segmentos de mercado, utilizando-se de estruturas de produção com distintos graus de sofisticação e eficácia. Essas empresas pertencem ao pólo cerâmico da região de Mogi-Guaçu e de São
Paulo, exceto a empresa "D", que está localizada em Santa Catarina.

Há também o caso da empresa "L", que direciona seus produtos para um nicho específico de mercado. Essa empresa, embora localizada no Estado de São Paulo, não está geograficamente próxima a nenhum dos quatro pólos cerâmicos anteriormente definidos.

Alguns movimentos de empresas pertencentes aos grupos estratégicos no setor também podem ser identificados. Um número significativo de empresas que se utilizam do processo de preparação da massa por via seca, concentradas na região de Santa Gertrudes, estão passando por um processo de profissionalização da administração, têm melhorado a qualidade (conformidade) de seus produtos e estão investindo na automação do processo de produção e no aumento da capacidade instalada. Por outro lado, as empresas que utilizam o processo de preparação da massa por via úmida, localizadas nos Estados de São Paulo e Santa Catarina, têm investido em novas tecnologias de produto e processo, na elaboração de design mais sofisticado e na verticalização para frente, integrando canais de distribuição e venda.

Em segundo lugar, e como conseqüência da existência de diversas combinações de estratégias, em cada grupo estratégico sobrevivem empresas com níveis de desempenho técnico e financeiro muito díspares e com estruturas de produção e de gestão, como já afirmamos, também bastante distintas em termos de sofisticação e de profissionalização. Não havendo informação segura sobre quais segmentos de mercado têm potencial maior de crescimento e lucratividade, sobre quais grupos estratégicos apresentam melhores condições de crescimento, sobre os níveis de desempenho das diversas empresas e tampouco sobre quais são as oportunidades de mercado e tecnológicas a aproveitar, há grande incerteza quanto às direções e ritmos das mudanças que serão implementadas pelas empresas em um futuro próximo (e que irão marcar a reestruturação do setor). 
Em terceiro lugar, a análise que fizemos até o momento indica que os demais tipos de empresas que constituem a cadeia industrial do setor de revestimentos cerâmicos influenciam o desempenho das empresas. Isso implica que as estratégias devem ser estabelecidas considerando as formas de relacionamento que uma empresa pode estabelecer e desenvolver com colorifícios, empresas de design, fornecedores de equipamentos, universidades e institutos de pesquisa etc. $\mathrm{O}$ estudo da cadeia industrial é portanto fundamental para compreensão do comportamento das empresas bem como para o direcionamento de programas setoriais.

Finalmente, já no nível mais restrito relacionado à estratégia de produção, observa-se que os segmentos de mercado, o mix de produtos e a tecnologia básica de produção estabelecidos nas estratégias competitivas das empresas condicionam suas estratégias de produção. Mas, mesmo assim, há ainda muitas alternativas para a escolha das características definidoras das áreas de decisão estrutural e infra-estrutural. Ou seja, dado um tipo de estratégia competitiva, é possível encontrar no setor empresas com estruturas de produção e de gestão muito diferentes. Como vimos nos casos examinados, as tecnologias de produto e de processo, os níveis de integração vertical, o número de linhas de produção em uma mesma planta, o grau de automação da produção, o nível de sofisticação dos sistemas de gestão, a qualidade de conformação e a qualificação dos administradores e trabalhadores são os mais variados. São portanto diversas as alternativas de combinação das estratégias competitivas e de produção nas empresas.

\section{Considerações Finais}

\footnotetext{
A demanda reprimida por habitação no mercado interno e as possibilidades de maior exploração do mercado externo (este último favorecido atualmente pela taxa de câmbio) oferecem boas perspectivas de desenvolvimento para o setor de revestimentos cerâmicos nos próximos anos.
}

Mesmo em uma situação favorável de mercado em que a demanda é crescente, não deixarão de existir pressões competitivas ocasionadas pela concorrência das 121 empresas existentes no setor de revestimentos cerâmicos e pela oferta de produtos substitutos tais como carpetes, pedras, pisos plásticos etc. As empresas que melhor definirem o seu posicionamento no mercado e que conseguirem desenvolver uma política para a manufatura adequada a esse posicionamento serão mais competitivas e, por conseqüência, poderão aumentar sua participação no mercado e melhorar sua lucratividade.

A pesquisa realizada nos permitiu verificar que as empresas desse setor se utilizam de diferentes estratégias competitivas e de produção, atuam com níveis significativamente diferentes de eficácia e rentabilidade e estão investindo na aquisição de novas tecnologias e na melhoria dos sistemas de gestão. Entretanto, ainda não foi possível, a partir das informações que levantamos, fazer qualquer tipo de prognóstico relativo às tendências de reestruturação do setor e às possibilidades de crescimento de cada grupo estratégico de empresas, dependendo de suas estratégias competitivas e de produção.

Todavia, podemos tecer algumas considerações a respeito dos grupos estratégicos. As empresas dos grupos 1 e 2, mais evoluídas do ponto de vista da gestão do sistema produtivo, ainda podem tornar-se mais eficazes a partir de investimentos nas áreas infra-estruturais. A flexibilidade, fator importante em suas estratégias competitivas, por exemplo, pode ser melhorada a partir de um sistema de planejamento e programação mais apurado. No que diz respeito à gestão da qualidade, embora todas as empresas desses grupos já tenham introduzido programas de melhoria, percebemos que existem espaços para aprimoramento do controle de processo e, principalmente, da relação com fornecedores.

As empresas dos grupos 3 e 5 também podem tornar-se mais competitivas trabalhando os fatores infra-estruturais relacionados aos sistemas de informação para PCP, à gestão da qualidade, 
à racionalização de processo etc., que terão impactos positivos em custos e em flexibilidade, fundamentais nas estratégias dos grupos 3 e 5, respectivamente.

Finalmente, o grupo 4, pelo posicionamento estratégico que ocupa (preço e variedade de produtos numa faixa intermediária com relação aos demais grupos), sofre pressões competitivas tanto das empresas do grupo 3 quanto das empresas dos grupos 1 e 2 . Os fatores pertencentes à área infra-estrutural também podem ser trabalhados de maneira a proporcionar aumento de competitividade para essas empresas.

Embora os resultados apresentados e analisados anteriormente suscitem novas questões a serem respondidas, entendemos que já oferecem muitas informações úteis para que acadêmicos ou profissionais ligados à indústria cerâmica as utilizem para conhecer aspectos da dinâmica do setor e para refletir a respeito das possibilidades de estratégias a serem adotadas pelas empresas.

Em continuidade a este trabalho pretendemos estudar com maior profundidade alguns grupos estratégicos de empresas, examinar com detalhes as estratégias de produção adotadas e as relações das empresas produtoras de revestimentos cerâmicos com os demais tipos de empresas pertencentes à cadeia industrial desse setor. Pretendemos, ainda, levantar alguns indicadores que nos permitam fazer inferências relativas às possibilidades de crescimento das empresas de acordo com o grupo estratégico ao qual as mesmas pertençam.

Outras pesquisas relacionadas aos diferentes pólos cerâmicos nacionais também seriam de extrema importância para o entendimento e a proposição de estratégias para a indústria de revestimento cerâmico, já que foi possível observar a existência de peculiaridades entre empresas de um mesmo pólo. Além disso, acreditamos que um melhor relacionamento entre empresas de uma mesma região e instituições de pesquisa pode fortalecer o setor, de maneira geral, contribuindo para que o país alcance um posicionamento privilegiado no mercado internacional.

\section{Referências Bibliográficas}

ADAIR, C.B. \& MURRAY, B.A.: Revolução total dos processos. São Paulo, Nobel, 1996.

ANFACER: Relatório da Associação Nacional dos Fabricantes de Cerâmica para Revestimentos. São Paulo, 28p., 1997.

ANFACER: Panorama da indústria cerâmica brasileira. São Paulo, 24p., 1999.

ASCER: Azulejos de España. <http://www.ascer.es/>. 1999.

COUTINHO, L.G. \& FERRAZ, J.C.: Estudo da competitividade da indústria brasileira. Campinas, Papirus, 1994.

GARVIN, D.A.: "Manufacturing Strategic Planning". California Management Review, summer, 1993.

GUPTA, Y.P. \& LONIAL, S.C.: "Exploring linkages between Competitive strategy, business strategy, and organizational strategy". Production and operations management, v. 7, n. 3, 243-264, 1998.
HAYES, R.H.: "Strategic planning - forward in reverse?". Harvard Business Review, nov-dec, 1985.

HÖRTE, S.A.; LINDBERG, P. \& TUNALV, C.: "Manufacturing strategies in Sweden". International Journal of Production Research, v. 25, n. 11, 1987.

LEONG, G.K.; SNYDER, D.L. \& WARD, P.T.: "Research in the process and content of manufacturing strategy". OMEGA International Journal of Management Science, v. 18, n. 2, 1980.

MILLS, J.; PLATTS, K. \& GREGORY, M.: "A framework for the design of manufacturing strategy processes: A contingency approach". Int. Journal of Operations \& Production Management, vol. 15, n. 4, 1995.

MONTGOMERY, C.A. \& PORTER, M.E.: Estratégia: a busca da vantagem competitiva. Rio de Janeiro, Campus, 1998. 
OHMAE, K.: The mind of strategist. Harmondsworth, Peguin Books, 1983.

OHMAE, K.: "Voltando à estratégia". In: MONTGOMERY, C.A. \& PORTER, M.E. Estratégia: a busca da vantagem competitiva. Rio de Janeiro, Campus, 1998.

PORTER, M.: Competitive advantage - Creating and Sustaining Superior Performance. New York, Free Press, 557p., 1985.

PORTER, M.E.: Competitive advantage. New York, The Free Press, 1985.

PORTER, M.E.: Competitive strategy. New York, The Free Press, 1980.

PRAHALAD, C.K. \& HAMEL, G.: “A competência essencial da corporação”. In: MONTGOMERY, C.A. \& PORTER, M.E. Estratégia: a busca da vantagem competitiva. Rio de Janeiro, Campus, 1998.
QUARESMA, H.U.: "Desafios da cerâmica". Mundo Cerâmico. Ano VII, nº 47, p. 36-38, julho de 1998.

SKINNER, W.: "Manufacturing-Missing Link in Corporate Strategy". Harvard Business Review, may-jun, 1969.

SKINNER, W.: “The Focused Factory". Harvard Business Review, 113-121, may-jun, 1974.

SOUZA, R. \& COVELO, M.A.: Estudo da Indústria Cerâmica para Revestimentos. Campinas: SCTE/ UNICAMP-FECAMP, 1993. 102p. (Relatório Técnico CTE 067/93. Projeto: Desenvolvimento Tecnológico e Competitividade da Indústria Brasileira).

VANALLE, R.M.: Estratégia de produção $e$ prioridades competitivas no setor de autopeças. São Carlos, EESC-USP, Tese de doutorado, 1995.

WHEELWRIGHT, S.C.: "Manufacturing strategy: defining the missing link". Strategic Management Journal, v. 5, 1984.

\title{
FIRMS OF CERAMIC TILES AND ITS COMPETITIVE AND MANUFACTURING STRATEGIES
}

\begin{abstract}
This paper addresses the competitive and manufacturing strategies implemented in twelve firms of Brazilian ceramic tiles industry. We have carried out interviews in the States of São Paulo and Santa Catarina and we have identified five strategic groups. It was possible to collect evidences that there are many possible combinations of competitive and manufacturing strategies. Even within each strategic group we have found very different manufacturing structures and management systems.
\end{abstract}

Key words: competitive strategy, manufacturing strategy, ceramic tile industry. 